\title{
A study on malassezia species causing superficial infections among patients attending a tertiary care hospital in Puducherry
}

\author{
Saranyaa $\mathbf{T}^{1}$, Swapna $\mathbf{M}^{2, *}$, Brindha G David ${ }^{3}$ \\ ${ }^{1}$ MBBS Student, Sri Venkateshwaraa Medical College Hospital and Research Centre, Puducherry, ${ }^{2}$ Assistant Director, Dept. of \\ Microbiology, Central Leprosy Teaching and Research Institute, Chengalpet, ${ }^{3}$ Associate Professor, Dept. of DVL, Sri \\ Venkateshwaraa Medical College Hospital and Research Centre, Puducherry, India
}

\author{
*Corresponding Author: Swapna M \\ Email: swapnamuthuswamy@gmail.com
}

Received: $5^{\text {th }}$ October, 2018

Accepted: $19^{\text {th }}$ November, 2018

\begin{abstract}
Introduction: Malassezia are normal resident flora in humans and are opportunistic in nature. Superficial infections caused by Malassezia include pityriasis versicolor, pityriasis capitis (dandruff), seborrheic dermatitis and folliculitis. Though the manifestations due to Malassezia are trivial, chronicity and recurrence of lesions are associated with social embarrassment and decreased self-esteem.

Aims and Objectives: The primary aim of the study was to detect the prevalence of Malassezia among superficial skin and scalp lesions. It also aims to compare Wood's lamp examination, $\mathrm{KOH}$ mount examination and culture for the diagnosis of Malassezia and study the percentage of various species of Malassezia responsible for superficial infections of skin and scalp.

Materials and Methods: One hundred samples collected from patients attending the Dermatology outpatient room with superficial infections of skin and scalp. Patients attending Dermatology outpatient room with complaints of hypopigmented / hyperpigmented / erythematous, scaly skin patches and patients attending Dermatology OP with complaints of itchy / non itchy scaly flakes of scalp (dandruff) were included in the study.

Results: Among the 100 samples, 77\% were Wood's lamp positive, 64\% were KOH positive and 59\% yielded growth of Malassezia in culture. Overall prevalence of Malassezia in our study was 59\%. In our study, M. globosa was the commonest species (57.62\%) followed by M. furfur and M. sympodialis.

Conclusion: Prevalence of Malassezia was 59\% in our study. Wood's lamp examination and KOH mount showed more positivity than culture. M. globosa was the most common species in the study. Wood's lamp and KOH mount can be used for diagnosis of Malassezia in resource poor settings. But culture and speciation should be performed wherever possible to avoid treatment failure and recurrences.
\end{abstract}

Keywords: Culture, Malassezia, Potassium hydroxide mount, Skin scrapings, Wood's lamp.

\section{Introduction}

The members of genus Malassezia are yeasts found in areas with numerous sebaceous glands due to their lipid requirement for growth. They are normal resident flora in humans and are opportunistic in nature. ${ }^{1}$ Alteration in normal skin flora and host's defense mechanism leads to colonization and infection due to Malassezia species. $^{2}$ The term superficial infection refers to the infections involving the outer layer of skin, hair and nail ${ }^{3}$ however, Malassezia species does not affect certain superficial sites like hair shaft, nail and mucus membrane. Superficial infections caused by Malassezia include pityriasis versicolor, pityriasis capitis (dandruff), seborrheic dermatitis and folliculitis. Malassezia infections are highly prevalent in hot and humid climate. ${ }^{4}$ Individuals with genetic predisposition, enhanced sebum secretion, hyperhydrosis and immunocompromised state are prone to develop infections due to Malassezia. Genus Malassezia includes fourteen species of which seven (Malassezia globosa, Malassezia restricta, Malassezia obtusa, Malassezia slooffiae, Malassezia sympodialis, Malassezia furfur and Malassezia pachydermatis) are frequently involved in causing disease. ${ }^{1}$ All the members of genus Malassezia are lipophilic except $M$. pachydermatis. ${ }^{5}$ Though manifestations due to Malassezia are trivial, chronicity and recurrence of lesions are associated with social embarrassment and decreased self-esteem. ${ }^{6}$ Malassezia species are known to produce biofilm, causing relapses. ${ }^{7}$ Malassezia infections are common in second decade of life and majority of adults seek medical advice for cosmetic reasons. Malassezia not only cause superficial infections, but also causes systemic infections like intravenous catheter induced fungemia, endocarditis, interstitial pneumonia and peritonitis. ${ }^{8}$

Though Malassezia is a normal skin flora, research on the topic is limited, because of its fastidious nature and tedious isolation procedure. ${ }^{5}$ Topical and oral azoles are active against Malassezia infections, except against inherently resistant Malassezia species (M. pachydermatis). ${ }^{9}$ There are reports of emerging resistance to terbinafine by various species of Malassezia. ${ }^{10}$ Inherent as well as emerging resistance explains the need for speciation to reduce the recurrence of lesions. ${ }^{1}$ Also, there is lack of data regarding the prevalence and distribution of various species of Malassezia in the population of our 
geographical region and therefore, this study has been conducted to isolate Malassezia from various superficial infections and speciate it based on standard procedures.

\section{Aims and Objectives}

The primary aim of the study was to detect the prevalence of Malassezia among superficial skin and scalp lesions. It also aims to compare Wood's lamp examination, $\mathrm{KOH}$ mount examination and culture for the diagnosis of Malassezia and study the percentage of various species of Malassezia responsible for superficial infections of skin and scalp.

\section{Materials and Methods}

This is a cross sectional study done in Sri Venkateshwaraa Medical College Hospital and Research Centre, Ariyur, Puducherry in 2017, with 100 samples collected from patients attending the Dermatology outpatient room with superficial infections of skin and scalp. Patients attending Dermatology outpatient room with complaints of hypopigmented / hyperpigmented / erythematous, scaly skin patches and patients attending Dermatology OP with complaints of itchy / non itchy scaly flakes of scalp (dandruff) were included in the study. Patients treated with topical/systemic antifungals within a month prior to the visit, patients who had done a hair wash on the day of visit and patients already diagnosed with infections due to other etiologies were excluded from the study. The study has been approved by the Institutional Research and Ethical Committee and samples were collected after obtaining written informed consent of the patients. Patients with suspected pityriasis versicolor, seborrhaeic dermatitis, folliculitis and pityriasis capitis were involved in the study. First, the lesions were examined by Wood's lamp in dark room for the presence of golden yellow fluorescence. Under aseptic precautions, scrapings of skin and scalp were taken from the site that had maximum scales or that showed maximum fluorescence. Samples were collected using a blunt scalpel or cellophane tape technique depending upon the amount of scales present. ${ }^{17}$ Flakes or scales if abundant were collected using the blunt scalpel and if only minimal scaling was present, samples were collected using a cellophane tape by placing the sticky surface of the tape over the lesion and peeling it off from the surface after sometime. Cellophane tape was stuck over the glass slide and transported to the laboratory. Ends of cellophane tape were crushed or stuck to a piece of paper for making it easier to separate. Scrapings were transported in a sterile Whatmann filter paper. $\mathrm{KOH}$ mount examination was performed by lifting the cellophane tape on the glass slide, adding drops of $20 \% \mathrm{KOH}$ and placing it back or placing few scales with drops of $\mathrm{KOH}$, covered with coverslip to detect the presence of hyphae and spores that exhibit the characteristic appearance of "spaghetti and meat balls". ${ }^{5}$ For culture, samples were inoculated in two Sabouraud's dextrose agar (SDA) slants containing chloramphenicol and cycloheximide of which one slant was layered with olive oil. Both SDA were incubated at $32^{\circ} \mathrm{C}$ for two weeks and examined once in two days for any visible growth. Chloramphenicol and cycloheximide supplement was added to prevent the growth of bacterial and saprophytic fungal contaminants. Species identification was performed as per routine microbiological methods (lipid dependence, morphology in Gram's stain, catalase test and growth at $\left.40^{\circ} \mathrm{C}\right){ }^{2}$ Results were tabulated and analyzed using simple percentage calculation.

\section{Observations and Results}

One hundred samples collected from symptomatic patients were processed to identify Malassezia. Age and sex distribution of patients, distribution of clinical samples, comparison of positivity by various methods (Wood's lamp, KOH mount and culture) and distribution of various species of Malassezia were shown in tables 1, 2, 3 and 4 respectively.

Table 1: Age and sex distribution of study subjects

\begin{tabular}{|l|c|c|c|}
\hline Age group & $\begin{array}{c}\text { Male } \\
\text { Number }(\boldsymbol{\%})\end{array}$ & $\begin{array}{c}\text { Female } \\
\text { Number }(\boldsymbol{\%})\end{array}$ & $\begin{array}{c}\text { Total } \\
\text { Number }(\boldsymbol{\%})\end{array}$ \\
\hline$<15$ years & $1(2.56)$ & $2(3.27)$ & $3(3)$ \\
\hline 16-30 years & $27(69.23)$ & $40(65.57)$ & $67(67)$ \\
\hline 31-45 years & $10(25.64)$ & $16(26.22)$ & $26(26)$ \\
\hline$>45$ years & $1(2.56)$ & $3(4.91)$ & $4(4)$ \\
\hline Total & $39(100)$ & $61(100)$ & $100(100)$ \\
\hline
\end{tabular}

Table 2: Distribution of clinical samples

\begin{tabular}{|l|c|c|}
\hline Clinical condition & Number & Percentage \\
\hline Pityriasis versicolor & 92 & 92 \\
\hline Seborrheic dermatitis & 0 & 0 \\
\hline Malassezia folliculitis & 0 & 0 \\
\hline Pityriasis capitis & 8 & 8 \\
\hline Total & 100 & 100 \\
\hline
\end{tabular}

Table 3: Comparison of Wood's lamp, KOH mount and culture

\begin{tabular}{|l|c|c|}
\hline \multicolumn{1}{|c|}{ Method } & $\begin{array}{c}\text { Number of } \\
\text { positives }\end{array}$ & $\begin{array}{c}\text { Percentage of } \\
\text { positives }\end{array}$ \\
\hline Wood's lamp & 77 & 77 \\
\hline KOH mount & 64 & 64 \\
\hline Culture & 59 & 59 \\
\hline
\end{tabular}

Table 4: Distribution of various species of Malassezia

\begin{tabular}{|l|c|c|}
\hline \multicolumn{1}{|c|}{ Species } & Number & Percentage \\
\hline Malassezia globosa & 34 & 57.62 \\
\hline Malassezia furfur & 12 & 20.33 \\
\hline Malassezia sympodialis & 11 & 18.64 \\
\hline Malassezia restricta & 1 & 1.69 \\
\hline Malassezia obtuse & 1 & 1.69 \\
\hline Total & 59 & 100 \\
\hline
\end{tabular}




\section{Discussion}

This is a cross-sectional study conducted to detect the prevalence, distribution of various species and compare various methods for diagnosis of Malassezia infections. We collected scrapings from skin and scalp from 100 symptomatic patients. Our study subjects were aged between 14 to 55 years. The youngest patient in our study was 14 years old. The study by Rudramurthy SM et al has shown that the youngest patient was 3 years old in their study. ${ }^{6}$ This shows that Malassezia infections are prevalent in young children. Eldest patient was 50 years in their study which was almost similar to our finding. For studying the age distribution, patients were categorized based on age into groups (Table 1). Least number of patients was seen in age group less than 15 years (3\%), followed by greater than 45 years $(4 \%)$. More than half of patients $(67 \%)$ were falling in the age group of 16 to 30 years. The study done by Moniri R et al showed similar finding, but the percentage was higher $(81 \%)$ compared to our study and the second most common age group was 31 to 45 years in their study, ${ }^{12}$ which is the same in our study (26\%).Gender distribution showed that among 100 patients in our study, 39 (39\%) were males and $61(61 \%)$ were females (Table 1$)$. This was different from the study done by Moniri $\mathrm{R}$ et al, ${ }^{12}$ but the study by Rudramurthy SM et al showed that females (61\%) were predominant in their study which supported our findings. ${ }^{6}$

Among the total 100 samples, 92 (92\%) samples were skin scrapings from suspected pityriasis versicolor and $8(8 \%)$ were scrapings of scalp from suspected pityriasis capitis. No patients with suspected seborrheic dermatitis or folliculitis were received during the two month study period (Table 2). In most of the subjects, hypopigmented or hyperpigmented patches were located in exposed parts of body and they sought medical help due to cosmetic reasons and fear of major skin diseases. Pityriasis capitis unless severe will not be exposed and that explains the fewer number of pityriasis capitis patients in our study. No subjects with suspected seborrheic dermatitis or folliculitis turned up during the study period may be due to mildness of symptoms. Among the patients with suspected pityriasis versicolor, 63 patients had lesions on the back, 59 patients had lesion on the chest, 32 had lesions on shoulders, 26 patients had lesions on neck, 17 had lesions in the face and 13 had on the upper limbs. This is exactly in concordance with the study done by Chaudhary et al where back was the commonly affected site followed by chest and neck. ${ }^{18}$ Dissimilar findings have been reported in the study done by Shah A et al, where neck was the common site affected. ${ }^{1}$ Among the patients with pityriasis versicolor, 87 (94.46\%) had multiple lesions in our study. The study by Chaudhary et al has reported that all their pityriasis versicolor patients had lesions at multiple sites. ${ }^{18}$ Among the skin lesions, hypopigmented lesions were seen in $94 \%$ and hyperpigmented in $6 \%$ of patients. This is similar to the observations in the study done by Chaudhary et al which showed 10\% and 90\% had hypo and hyperpigmented lesions respectively. In the study by Archana BR et al, hyperpigmented lesions were seen in higher percentage $(26 \%)$, though not predominant. ${ }^{14}$ Eight patients in our study had pityriasis capitis, among which one patient had pityriasis versicolor also.

Comparison of three methods (Wood's lamp examination, $\mathrm{KOH}$ mount examination and culture on SDA with chloramphenicol and cycloheximide with olive oil overlay) showed that Wood's lamp was more sensitive than $\mathrm{KOH}$ mount and culture. Among the 100 samples, $77 \%$ were Wood's lamp positive, $64 \%$ were $\mathrm{KOH}$ positive and 59\% yielded growth of Malassezia in culture (Table 3). Among 59 isolates, two were from suspected pityriasis capitis and remaining 57 were from suspected pityriasis versicolor. According to the study done by Kaur M et al, $46.66 \%$ were culture positive. ${ }^{19}$ According to the study done by Moniri $\mathrm{R}$ et al, on pityriasis versicolor patients, $94.21 \%$ were positive by $\mathrm{KOH}$ examination and $92.6 \%$ were positive by culture. $^{12}$

Higher positivity of Wood's lamp and $\mathrm{KOH}$ mount examination than culture was attributable to nonspecific fluorescence or other yeasts which could be misinterpreted as Malassezia respectively. Culture was taken as gold standard and prevalence was calculated based on culture positivity. Overall prevalence of Malassezia in our study was $59 \%$. Percentage positivity of Malassezia in pityriasis versicolor was $61.95 \%$ and in pityriasis capitis was $25 \%$. In our study, M. globosa was the commonest species $(57.62 \%)$ followed by $M$. furfur and M. sympodialis. (Table 4) Most prevalent species in pityriasis versicolor was $M$. globosa. In pityriasis capitis, only two isolates were obtained, $M$. restricta and M. sympodialis one each. According to the study done by Kaur $\mathrm{M}$ et $\mathrm{al},{ }^{19} M$. globosa was the commonest species followed by $M$. sympodialis, $M$. obtusa and M. furfur. Necessity for speciation is evident from the study performed by Rojas FD et al, which showed $M$. furfur was the least susceptible and $M$. sympodialis was the most susceptibile species of Malassezia. $^{19}$

\section{Conclusion}

Prevalence of Malassezia was 59\% in our study. Wood's lamp examination and $\mathrm{KOH}$ mount showed more positivity than culture. M. globosa was the most common species in the study. Among pityriasis versicolor, M. globosa was the commonest and $M$. restricta and $M$. sympodialis one each was isolated in pityriasis capitis. Wood's lamp and $\mathrm{KOH}$ mount can be used for diagnosis of Malassezia in resource poor settings. But culture and speciation should be performed wherever possible to avoid treatment failure and recurrence. 


\section{Acknowledgement}

Authors would like to acknowledge the financial support provided by ICMR to the first author (Reference ID: 2017-03681)

\section{References}

1. Shah A, Koticha A, Ubale M, Wanjare S, Mehta P, Khopkar U. Identification and speciation of Malassezia in patients clinically suspected of having Pityriasis versicolor. Indian J Dermatol. 2013;58:239.

2. Chander J. Malassezia Infections. In Textbook of Medical Mycology, $3^{\text {rd }}$ d, New Delhi, Mehta Publishers, 2009, pp 92-105

3. Mahmoudabadi AZ, Zarrin M, Mehdinezhad F. Seborrheic dermatitis due to Malassezia species in Ahvaz, Iran. Iran J Microbiol. 2013;5:268-71.

4. Erchiga CV, Hay R. Pityriasis versicolor and other Malassezia skin diseases In: Boekhout T, Gueho E, Mayser P, Velegraki A (Hrsg) Malassezia and the skin science and clinical practice. Springer, Berlin; 2010.

5. Thayikkannu AB, Kindo AJ, Veeraraghavan M. Malassezia - Can it be Ignored? Indian J Dermatol. 2015;60(4):332-339. doi: 10.4103/0019-5154.160475

6. Rudramurthy SM, Honnavar P, Dogra S, Yegneswaran PP, Handa S, Chakrabarti A. Association of Malassezia species with dandruff. Indian J Med Res. 2014;139:431-7.

7. Allen HB, Goyal K, Ogrich L, Joshi S. Biofilm Formation by Malassezia Furfur/Ovale as a Possible Mechanism of Pathogenesis in Tinea Versicolor. J Clin Exp Dermatol Res. 6:311. doi:10.4172/2155-9554. 10000311

8. Gaitanis G, Magiatis P, Hantschke M, Bassukas ID, Velegraki A. The Malassezia genus in skin and systemic diseases. Clin Microbiol Rev. 2012;25:106-41.

9. Velegraki A, Cafarchia C, Gaitanis G, Iatta R, Boekhout T. Malassezia Infections in Humans and Animals: Pathophysiology, Detection, and Treatment. PLoS Pathog. 11(1):e1004523. doi: 10.1371 /journal .ppat. 1004523

10. Gupta AK, Kohli Y, Li A, Faergemann J, Summerbell RC. In vitro susceptibility of the seven Malassezia species to ketoconazole, voriconazole, itraconazole and terbinafine. Br J Dermatol. 2000;142:758-65

11. Gupta AK, Batra R, Bluhm R, Boekhout T, Dawson TL. Skin diseases associated with Malassezia species. $J \mathrm{Am}$ Acad Dermatol. 2004;51:785-98.

12. Moniri R, Nazeri M, Amiri S, Asghari B. Isolation and identification of Malassezia spp. In pytiriasis versicolor in Kashan, Iran. Pak J Med Sci. 2009;25(5):837-840.
13. Chua KB, Chua IY, Chua IE, Chong KH, Chua KH. A modified mycological medium for isolation and culture of Malassezia furfur. Malaysian J Pathol. 2005;27:99-105.

14. Archana BR, Beena PM, Kumar S. Study of the distribution of Malassezia species in patients with pityriasis versicolor in Kolar Region, Karnataka. Indian J Dermatol. 2015;60:321.

15. Promanik SB, Chakraborty A, Nandi A, Banerjee M, Ghosh R, Bandopadhyay M et al. A study of prevalence of different species of Malassezia causing pityriasis versicolor and sites of distribution of lesion in a tertiary care hospital in Kolkata, India. Int J Curr Microbiol App Sci. 2015;4:471-8.

16. Giusiano G, Sosa ML, Rojas F, Vanacore ST, Mangiaterra M. Prevalence of Malassezia species in pityriasis versicolor lesions in Northeast Argentina. Rev Iberoam Micol. 2010;27:71-4. doi:10.1016/j.riam.2009. 12.005

17. Kurade SM, Amladi SA, Miskeen AK. Skin scraping and a potassium hydroxide mount. Indian J Dermatol Venereol Leprol. 2006;72:238-41.

18. Chaudhary R, Singh S, Banerjee T, Tilak R. Prevalence of different Malassezia species in pityriasis versicolor in central India. Indian J Dermatol Venereol Leprol. 2010;76:159-64.

19. Kaur M, Narang T, Bala M, Gupte S, Aggarwal P, Manhas A. Study of the distribution of Malassezia species in patients with pityriasis versicolor and healthy individuals in Tertiary Care Hospital, Punjab. Indian J Med Microbiol. 2013;31:270-4.

20. Rojas FD, Sosa ML, Fernandez MS, Cattana ME, Cordoba SB, Giusiano GE. Antifungal susceptibility of Malassezia furfur, Malassezia sympodialis and Malassezia globosa to azole drugs and amphotericin B evaluated using a broth microdilution method. Med Mycol. 2014;52:641-6. doi: 10.1093/mmy/myu010

How to cite this article: Saranyaa T, Swapna M, David B.G. A study on malassezia species causing superficial infections among patients attending a tertiary care hospital in Puducherry. Indian $\mathbf{J}$ Microbiol Res. 2018;5(4):484-487. 